
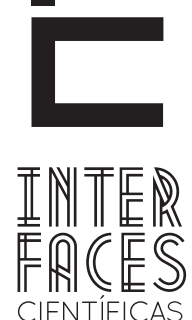

HUMANASE SOCIAIS

\title{
SER PROFESSOR EM TEMPOS ATUAIS: REPRESENTAÇ̃̃ES DE ESTUDANTES DAS LICENCIATURAS DA UEFS
}

Antonio Roberto Seixas da Cruz ${ }^{1}$

Murilo Oliveira Almeida²

\section{RESUMO}

0 presente artigo objetiva refletir sobre as representações sociais de estudantes dos cursos de licenciatura da Universidade Estadual de Feira de Santana (UEFS) sobre ser professor, a partir das experiências vivenciadas em sua trajetória de formação acadêmica. O quadro teórico do estudo baseou-se na Teoria das Representações Sociais - TRS (MOSCOVICI, 1987; JODELET, 2001), e nos conceitos de profissão docente (GARCIA, 2005) e identidade profissional (VALLE, 2002; GARCIA, 2005). Optamos por uma pesquisa de abordagem qualitativa. Os dados foram coletados e produzidos por meio das seguintes estratégias: realização de dois grupos focais (o primeiro formado por dez estudantes e o segundo formado por sete) matriculados no último semestre dos cursos de Licenciatura da UEFS; e entrevista semiestruturada. Os resultados da pesquisa indicam que a docência ainda é vista, na atualidade, como profissão menor, uma subprofissão e uma área em que qualquer um que tenha algum tipo de formação, poderá atuar.

\section{PALAVRAS-CHAVE}

Docência. Profissionalização. Teoria das Representações Sociais (TRS). 


\section{ABSTRACT}

This article aims to reflect on the social representations of bachelor students of State University of Feira de Santana (UEFS) about being a teacher, from the experiences in its trajectory experienced academic training. The theoretical framework of the study was based on the Social Representations Theory - SRT (MOSCOVICI, 1987; JODELET, 2001), and on the concepts of teaching profession (GARCIA, 2005) and professional identity (VALLE, 2002; GARCIA, 2005). We chose a qualitative research approach. The data were collected and produced through the following strategies: two focus groups (the first consisting of ten students and the second consisting of seven) enrolled in the last semester of Undergraduate courses of the UEFS; and semistructured interviews. Survey results indicate that teaching is still seen, nowadays, as minor profession, a subprofission and an area in which anyone who has some kind of training can act.

\section{KEYWORDS}

Teaching. Professionalization. Social Representations Theory (SRT).

\section{RESUMEN}

Este artículo pretende reflexionar sobre las representaciones sociales de los estudiantes de licenciaturas en la Universidad Estadual de Feira de Santana (UEFS) de ser un maestro, de las experiencias en su trayectoria de formación académica. El marco teórico del estudio basado en la teoría de las representaciones sociales-TRS (MOSCOVICI, 1987; JODELET, 2001) y en los conceptos de enseñanza de la profesión (García, 2005) y la identidad profesional (VALLE, 2002; GARCÍA, 2005). Optamos por una investigación cualitativa. Los datos fueron recogidos y producidos a través de las siguientes estrategias: dos grupos de enfoque (el primer compuesto de diez estudiantes y el segundo que consta de siete) inscrito el semestre pasado de cursos de pregrado de la UEFS; y entrevista semiestructurada. Resultados de la encuesta indican que la enseñanza es todavía considerada, hoy en día, una profesión, un subprofesión más pequeño y un área en que cualquiera que tenga cualquier tipo de entrenamiento, usted puede actuar.

\section{PALABRAS CLAVE}

Enseñanza. Profesionalización. Teoría de las representaciones sociales (TRS). 


\section{INTRODUCÃO}

Grande parte das sociedades humanas está vivenciando profundas transformações em todos os setores, na economia, na política, e, principalmente no avanço desenfreado das novas tecnologias. Essas mudanças afetam a forma dos sujeitos pensarem o mundo por causa das novas descobertas inimagináveis, refletindo na maneira como a sociedade, bem como os professores e estudantes representam e encaram a educação em todos os seus níveis (KENSKI, 2011).

Porém, as velozes transformações tecnológicas impõem novos ritmos e dimensões aos processos que envolvem ensino-aprendizagem. Atualmente, os sujeitos praticamente são forçados a buscarem formação independentemente do grau de escolarização alcançado. Além disso, existem diversos espaços que apresentam informações e conhecimentos a que se pode ter acesso, não sendo mais necessário deslocar-se fisicamente até as instituições tradicionais de ensino para aprender (KENSKI, 2011).

Nesse contexto, o presente artigo se concentrará especificamente na abordagem das alterações filosófico-epistemológicas que estão subjacentes às práticas pedagógicas cotidianas dos professores, seja na Escola Básica, seja do Ensino Superior e que, consequentemente fundamentam a educação e afetam a forma de ser e de estar dos indivíduos. No bojo dessas mudanças, encontram-se aquelas ligadas à forma de educar os sujeitos, seja na sociedade como um todo, seja na escola, instituição responsável pela educação formal.

Assim, os modelos educacionais vêm sofrendo profundas modificações, as quais afetam tanto a identidade e o papel do professor quanto o papel do estudante. Este, anteriormente, era considerado como um "papel em branco", sujeito passivo, que deveria sofrer a ação do professor, sendo este último considerado detentor do saber. Entretanto, a partir de transformações culturais, sociais e econômicas, bem como do surgimento de teorias que se debruçam sobre o papel do professor e do estudante no processo ensino-aprendizagem, passou-se a esperar desses sujeitos uma interação que transponha as barreiras meramente mecanicistas do ensinar e aprender.

Dessa maneira, o professor tem sido impelido a refletir sobre sua prática pedagógica com vistas a transformá-la, fundamentando sua docência em teorias educacionais, fato que altera não só a postura docente em sala de aula, mas, também, exige a (re)significação de sua identidade profissional.

Assim, foi a partir dessas reflexões que nasceu a ideia de pesquisar a respeito da temática que trata este artigo e responder a seguinte questão: quais as representações sociais de estudantes dos cursos de licenciatura da Universidade Estadual de Feira de Santana (UEFS) sobre o ser professor, construídas durante sua trajetória de formação acadêmica?

Para tanto, fez-se necessário perceber quais paradigmas, ao longo do processo histórico, fundamentaram e fundamentam a construção da docência, tanto na prática pedagógica cotidiana, quanto nas vivências pessoais, as quais são responsáveis pela constituição desse sujeito social e profissional.

Behrens (2003) apresenta o paradigma tradicional (Cartesiano-Newtoniano), que surgiu a partir do século XVII com o pensamento de René Descartes (1596-1650), Galileu Galilei (1564-1642) e, posteriormente, de Isac Newton (1643-1727). Tal paradigma, ao tempo em que dá uma grande contribuição à Ciência, apresenta uma mentalidade 
reducionista de mundo, da sociedade e do sujeito, com seus elementos mecanicistas. Esses pressupostos científicos influenciaram na constituição, no século XIX, da corrente filosófica positivista, que reforça a separação entre corpo e mente, sujeito e objeto do conhecimento, razão e emoção, construindo uma ciência dualista (BEHRENS, 2003).

Essa postura epistemológica influenciou os diversos campos da ciência, entre os quais destacamos aqueles que tratam da educação formal. Desta maneira, a escola passa a ser vista como uma instituição que deveria apenas repassar os conhecimentos produzidos no âmbito da ciência. Evidentemente, não seriam todos os conhecimentos, apenas aqueles necessários aos sujeitos no exercício de suas atividades profissionais e ao convívio social baseado nos ideários de "ordem e progresso”. Em consequência, o professor é considerado como o detentor do conhecimento e o discente mero receptáculo.

No século XX, com o desenvolvimento tecnológico que se deu com o surgimento das "sociedades" do conhecimento e da informação, advindo do aparecimento das Novas Tecnologias, tendo como principais características a explosão e diversificação de informações, é que começam as primeiras críticas ao modelo positivista, o qual apresenta uma mentalidade reducionista e técnica, que se intensificam, no Brasil, na década de 1950 do século XX, com o advento do desenvolvimentismo tecnológico-industrial (BERHENS, 2003).

Essas mudanças provocam uma crise nesse modelo até então aceito para a prática educativa. A crise desse paradigma tradicional que predominava, mostra que esse não consegue responder à complexidade e diversidade vivenciadas pelos seres humanos no momento atual. Atribui-se a essas transformações às novas perspectivas e teorias que surgiram a partir do século XIX e início do século
XX. Dentre elas se destacam: a "Teoria da Evolução da Espécie”, de Jean Baptiste Lamarck (1744-1859) e Charles Darwin (1809-1882); a "Teoria da Relatividade", de Albert Einstein (1879-1955,) e a “Teoria Quântica" de Max Planck (1858-1947), que juntas começaram a provocar um novo modo de pensar o mundo, agora em movimento, complexo, dinâmico, indivisível, desordenado, instável, flutuante, visto a partir de um pluralismo de ideias, total e formado segundo uma rede de relações.

Nesse sentido, os estudos de Jean Piaget (1896-1980) e Lev Vygotsky (1896-1934) propunham, também, uma alteração no modo de pensar o sujeito, especificamente, no que se referem os processos de ensino-aprendizagem.

Dessa maneira, para Castorina (1996, p. 12),

A teoria piegetiana é apresentada como uma versão do desenvolvimento cognitivo nos termos de um processo de construção de estruturas lógicas, explicada por mecanismos endógenos, e para a qual a intervenção social externa só pode ser "facilitadora" ou "obstaculizadora".

Assim, o construtivismo piagetiano concebe o sujeito como um ser biológico que avança na construção do conhecimento a partir de estágios de desenvolvimento marcados por características mais ou menos definidas (CASTORINA, 1996).

Outra concepção de ser humano surge para ajudar a abalar a postura de educação tradicional, trata-se do sociointeracionismo, conforme pode ser visto a seguir:

\footnotetext{
A teoria de Vygotsky aparece como uma teoria his tórico-social do desenvolvimento que, pela primeira vez, propõe uma visão da formação das funções psíquicas superiores como 'internalização' mediada da cultura e, portanto, postula um sujeito social que não é a apenas ativo mas sobretudo interativo. (CASTORINA, 1996, p. 12).
} 
Assim, essas perspectivas teóricas defendem que o conhecimento se constrói a partir das interações que os sujeitos estabelecem com o "mundo" ou com os outros seres, e que o professor tem o papel de mediar essa construção na sala de aula. Ambas as teorias tendem a questionar o paradigma dominante, desviando a atenção do sujeito que ensina para os processos de aprendizagem daquele que aprende, sendo este o principal ator do processo.

Outra teoria contribuiu para abalar o modelo positivista de produção do saber, que coincide com o modelo tradicional de ensino: o Materialismo Histórico Dialético, cunhado por Karl Marx (1818-1883) e Friedrich Engels (1820-1895), e por aqueles que o sucederam.

Segundo Minayo (1996, p. 75-76),

O marxismo aborda o processo histórico com esquemas universalizantes e totalizantes. [...] Mas em nenhum caso, nos trabalhos de Marx, esta perspectiva pretende impedir ou tornar útil a apreciação do processo como totalidade singular: ele tenta mostrar os fatos no pormenor e no conjunto. Se ele subordina os fatos anedóticos à totalidade, é através daqueles que pretende descobrir esta. [...] Assim o marxismo vivo é heurístico: com relação à pesquisa concreta, seus princípios e seu saber anterior aparecem como reguladores.

Os escritos do autor revelam uma crítica à concepção positivista, pois ele traz para o debate da produção do conhecimento os aspectos históricos numa perspectiva que dialoga com as questões totalizadoras e universalizantes, propondo então, uma concepção de reflexão social complexa que trata ao mesmo tempo dos aspectos particulares e do conjunto dos fatos na tentativa de explicação da "realidade".

Além dos marxistas, outros teóricos, como Herbert Marcuse (1898-1979), Theodor Adorno (19031969), Max Horkheimer (1895-1973), Walter Benjamin (1892-1940), Jüger Habermas (1929), filiados à Escola de Frankfurt, fundada em 1924, vieram a questionar os modelos positivista, estruturalista e mesmo o marxista que não mais davam conta de explicar a realidade complexa vivenciada por muitas das sociedades do Planeta.

Esses autores formularam a Teoria Crítica, que tende a criticar a abordagem marxista que, segundo o Dicionário de Filosofia Moral e Política do Instituto de Filosofia da Linguagem (2002, p. 1) pode ser apresentada da maneira como se segue:

Em 1937 Horkheimer publica na revista "Zeitschrift fur Sozialforshung", (Jornal para a Investigação Científica), o artigo "Traditionelle und Kritsche", ("Teoria Tradicional e Teoria Crítica"), no qual formula pela primeira vez a natureza e a finalidade de um novo gênero de teoria, a crítica da sociedade, por oposição à concepção teórica tradicional, que defendia uma distinção entre o nível do conhecimento (teoria) e o da transformação histórica (prática). Daí a sua atitude crítica em relação à filosofia não-idealista, quer em relação às filosofias empiristas suas coevas, acabando por propor uma filosofia que realmente desse conta da evolução da razão humana no tempo.

Tais críticas afetaram profundamente o modelo de produção de conhecimento baseado na objetividade e, também, a própria forma de a escola desempenhar o seu papel, o que alterou as propostas pedagógicas e a docência em todos os seus níveis.

No contexto histórico dessas transformações, conhecer as representações sociais dos estudantes dos cursos de licenciatura da UEFS sobre ser professor, a partir das experiências vivenciadas na trajetória de formação acadêmica, torna-se o objetivo desse trabalho.

O quadro teórico do estudo foi embasado na Teoria das Representações Sociais (TRS) de Serge Moscovici (1987). Para Moscovici (1987, p. 28), as RS são "um corpus organizado de conhecimentos e uma das atividades psíquicas graças às quais os homens tornam inteligível a realidade física 
e social, inserem-se num grupo ou numa ligação cotidiana de trocas e liberam os poderes de sua imaginação”.

Segundo Jodelet (2001, p. 22) as RS consistem em,

Uma forma de conhecimento socialmente elaborada e partilhada com um objetivo prático e que contribui para a construção de uma realidade comum a um conjunto social. Nesse sentido, elas são concebidas como um saber gerado através de comunicações da vida cotidiana, com o objetivo prático de orientação de comportamentos em contextos sociais concretos.

A escrita do estudo baseou-se nessa teoria, pois visou destacar a fala dos sujeitos dessa pesquisa, entendendo-os como os principais agentes do processo educativo, caracterizado, assim, como fenômeno eminentemente social, e por isso, humano.

Para alcançar o objetivo proposto, optamos por uma pesquisa descritiva de abordagem qualitativa. Os dados da investigação foram coletados e produzidos por meio de dois grupos focais, um formado por dez estudantes e outro por sete, matriculados no último semestre dos cursos de licenciatura da UEFS que, voluntariamente, aceitaram participar da pesquisa. Como estratégia de coleta e produção de dados, utilizamos a entrevista semiestruturada, com vistas a responder a questão norteadora da pesquisa: quais as representações sociais de estudantes dos cursos de licenciatura da UEFS sobre ser professor, a partir das experiências vivenciadas em sua trajetória de formação acadêmica.

O presente trabalho vincula-se ao Núcleo de Estudos e Pesquisa sobre Pedagogia Universitária (NEPPU), formado por pesquisadores na área de educação e por bolsistas de Iniciação Científica que apóiam os docentes em suas diversas atividades no Núcleo e apresentam contribuições às pesquisas, por meio de seus respectivos planos de trabalhos.

Este artigo desenvolve-se em duas perspectivas: a primeira consiste em uma reflexão a res- peito da relação entre docência e profissionalismo, articulada com os depoimentos dos sujeitos entrevistados; a segunda trata de discutir sobre a relação mútua entre a prática do professor e sua identidade profissional, relacionando-as com as entrevistas realizadas com os discentes.

\section{PROFISSÃO DOCENTE}

Existe uma tendência social em reconhecer e prestigiar algumas profissões, tais como a Medicina, a Engenharia, o Direito entre outras. Tal postura desvaloriza outros ofícios, que são consideradas de menor prestígio. Entre essas carreiras podemos destacar aquelas ligadas ao magistério primário e ao ensino superior (GARCIA, 2005).

Essa visão pauta-se na existência da especialização dos conhecimentos nos diversos campos, que se alicerçam em "certezas científicas” e em uma cultura técnica comungada pelos diversos grupos profissionais. Sobre esses aspectos, um dos depoentes afirma:

Essa fragilidade na nossa profissão, qualquer um pode ser professor. Porque sabendo falar e explicar as coisas você pode ser professor. [...] Qualquer um pode. Só é se expressar bem que você já pode ser professor. Então não há uma necessidade de você se qualificar e você se profissionalizarem. (PARTICIPANTE 5).

Segundo o depoimento, o desprestígio do professor se dá pela falta de exigência de capacitação profissional, inicial e continuada e a inexistência de critérios de qualidade para o exercício da profissão docente.

Outro sujeito da pesquisa corrobora com a importância da formação do professor para uma melhor atuação profissional, bem como na busca de uma melhor definição de seu campo de trabalho, conforme se pode ver a seguir: 
Pude observar a atuação de muitos professores que, talvez, não tenham sido formados para estarem ali [...] Então não tiveram ali a sua formação teórica, não tiveram ali a preparação para estarem em sala de aula e por isso também as várias deficiências que a gente percebeu durante a formação no bacharelado [...] Professores dotados de um máximo de conhecimento sobre o assunto, sobre a disciplina, mas que não tinham como transmitir, não tinham, em si, adquirido em sua vida as ferramentas necessárias para transmitir e mediar aquele conhecimento [...] Não existe na questão da formação do professor uma teoria sem prática, assim como é muito difícil você aplicar, partir para a prática se você não tiver uma fundamentação teórica consistente. Eu não vejo como distanciar teoria de prática. (PARTICIPANTE 4).

A fala desse estudante indica que o professor precisa estar atento para a relação existente entre teoria-prática na sua docência, entre outras questões, pois são necessários conhecimentos específicos referentes à sua área de atuação.

Outro depoente revela que a sua opção pela docência está ligada, intimamente, à questão da sobrevivência. Percebe-se tal postura na fala que se segue,

Eu resolvi fazer história não tanto pela questão de ser, de gostar de ser professora, assim, gostava da área de história, achava interessante, mas a questão de ensinar história, além de ter certo preconceito na sociedade assim, ah, você é professora, sabe? Entrou na universidade para ser professora? Além de ter isso, ainda tem com certeza, não me agradava muito como os professores, toda aquela algazarra de sala de aula, aquela agonia toda, os professores lá sempre reclamando do salário, aquela coisa toda assim, sabe? Eu sempre tive uma visão meio depreciativa do que é ser professor. A área de ser professor, de ser profissional, ser docente no caso, eu optei mais porque, assim, geralmente falava que era uma área que tem muito emprego [...]. (PARTICIPANTE 13).

0 excerto citado anteriormente revela que o desprestígio social da docência é um dos aspectos que tendem a depreciar a profissão, pois, nem sempre a escolha da carreira significa que o pro- fessor sinta-se pertencente a um campo de trabalho com o qual se identificou. Em seu depoimento, expressa que a docência ainda é uma carreira que emprega muitas pessoas.

Corroborando com essa mesma questão outro depoente diz que,

[...] Não podemos desqualificar esse profissional, mas ele não pega as disciplinas para capacitar, para trabalhar na alfabetização. Se a gente da Pedagogia, que vê uma disciplina só, tem todas essas dificuldades, imagina uma pessoa que direcionou o seu curso todo para trabalhar com gente de $5^{\mathrm{a}}$ ao ensino médio, no fundamental de segundo ciclo, e ensino médio? Então fica um pouco complicado, e então se perdeu muito essa característica da profissionalização do professor, o professor ainda não tem essa característica de profissão [...]. (PARTICIPANTE 6).

Para esse estudante, o sentido de profissionalização ainda não está presente na docência, inclusive porque se afirma que o professor não tem certas características profissionais. Dessa forma, exige-se do docente uma postura de profissional, todavia, o que se pode perceber é que a docência ainda é uma profissão em construção.

Nessa perspectiva, existe um modelo de profissionalismo denominado por trabalho complexo, o qual possibilitou que ocorressem mudanças na concepção de formação acadêmica dos professores.

Diante desse processo de mudanças nos modelos de profissionalismos docente, analisando-se o sistema de ensino brasileiro, observa-se que a construção de uma "identidade profissional" está ligada ao fenômeno de profissionalização, implementado pelas reformas educacionais do regime autoritário. Este fenômeno abrange fundamentalmente duas dimensões: a organização burocrática (e hierárquica) da administração educacional e a elevação dos níveis de formação do corpo docente. "A profissionalização conjuga, portanto interesses comuns e contraditórios das esferas administrativas, das esferas representativas do pessoal da educação e dos próprios professores" (VALLE, 2002, p. 214). 
Com o passar do tempo e com as transformações políticas, econômicas e sociais, os profissionais da educação tornaram-se mais qualificados e, a partir de meados da década de 1980, configuraram-se em um corpo que tendia a absorver elementos de diversas áreas de produção do saber e de práticas educacionais, tais como: a sociologia, a teoria social, a psicologia infantil, as teorias da aprendizagem, aspectos que contribuíram para complexificar sua docência (GARCIA, 2005).

Nesse sentido, exige-se do professor que seja um novo sujeito, ou seja, que exerça novos papéis dentro da sua profissão, o que poderá esbarrar no equívoco de considerar que o docente deva atuar em diversas funções no contexto escolar, como pode ser percebido a seguir:

[...] Quando eles realmente falaram do professor artista, eles estavam falando do professor [...] "tapa-buraco", aquele que tem que estar tapando os buracos da educação, e não o professor que vai a luta, que sabe que é difícil que ainda sofre retaliações, mas daquela visão que se não tem porteiro, eu faço papel de porteiro, se não tem coordenador, eu faço papel de coordenador. Agora eu não fui capacitada, vamos dizer assim, para fazer papel nem de coordenador, nem de porteiro. (PARTICIPANTE 1).

É possível observar na fala desse entrevistado, a denúncia sobre a desvalorização do docente e de sua profissão. Segundo o depoimento, é necessária uma capacitação profissional em serviço e um compromisso do Estado com políticas públicas eficientes que visem instaurar uma cultura de valorização do magistério, em todos os níveis.

Outra questão a ser ressaltada, é que os modelos de profissional são construídos historicamente e complementam-se, ou seja, essas alterações nas concepções de profissionalização docente não ocorrem dissociadas das transformações por que passa a sociedade, nem tampouco se excluem entre si. Além disso, encontram-se no contexto da dinâmica social não sendo, pois, categorias de análise estanques e dissociadas da realidade mais ampla.
Dessa forma, em contraposição ao trabalho complexo, Hargreaves e Goodson (1981, apud GARCIA, 2005) defendem um profissionalismo interativo ou "pós-moderno" que, ao contrário dos modelos anteriores, encaixar-se-ia nos paradigmas da "pós-modernidade" apresentando uma perspectiva integrativa, uma melhoria do trabalho profissional e da qualidade do ensino.

Nessa perspectiva, o depoente fala da importância da coparticipação e integração dentro da atuação profissional para uma melhoria da qualidade docente, como se pode ver a seguir:

[...] Eu não gosto da palavra de direção, porque parece que você colocou os alunos ali na frente, botou a carroça lá atrás e ta "vai pra aqui, vai pra ali” e não é assim. Existe o trabalho de construção, tem que haver um trabalho de construção conjunta. (PARTICIPANTE 1).

Segundo o entrevistado, o trabalho docente, na atualidade caracteriza-se pela participação efetiva dos membros desse processo de construção, sendo importante sair da perspectiva da direção autoritária dada pelo professor, e ir para a busca de uma aprendizagem na qual professor e estudante estejam integrados, sendo que, este último tem como função, também, produzir conhecimentos.

Referindo-se ao profissionalismo interativo ou "pós-moderno", podemos listar algumas características desse modelo: existe um aumento das oportunidades e responsabilidades para julgar temas do ensino, currículo e cuidados que afetam o aluno; articulação entre os propósitos morais, sociais e os valores do que ensinar, como os problemas de currículo e avaliação; a necessidade do trabalho docente em culturas colaborativas de apoio, no intuito da partilha do conhecimento especializado para a resolução dos problemas da prática, e não em trabalhos conjuntos que implementam as ordens externamente (GARCIA, 2005). 
Nesse sentido, é imprescindível a luta e a busca por uma aprendizagem contínua ao invés da complacência com obrigações enfraquecedoras, bem como "reconhecimento das tarefas de alta complexidade, com níveis de status e remuneração apropriados para tal complexidade" (GARCIA, 2005, p. 53).

Dessa maneira, tais modelos, explicitados anteriormente, contribuem para uma melhor compreensão das implicações das reformas legislativas e transformações na profissão do professor, sobre o cotidiano escolar e a identidade profissional dos docentes, porém, são categorias analíticas que visam mostrar possibilidades e implicações que convivem em contradição, pois não são fixas, estão numa rede de tensões e contradições. Assim, é no bojo dessas transformações sociais e profissionais que a docência vem se constituindo ao longo do tempo.

\section{IDENTIDADE PROFISSIONAL: O SER PROFESSOR}

A identidade profissional é formada por aspectos individuais, sociais e político-ideológicos que tornam seu processo de construção lento, dinâmico e complexo. Nessa perspectiva, segundo Valle (2002), a identidade profissional está ligada ao fenômeno da profissionalização implementado pelas reformas educacionais do Regime Autoritário-Ditatorial Brasileiro (1964-1985), que apresentam uma organização burocrática da administração educacional e a elevação dos níveis de formação docente, pois conjuga interesses comuns e contraditórios das esferas administrativas, dos representantes da educação e dos próprios professores.

Entendendo a identidade profissional como uma prática que vem se constituindo a partir das transformações advindas das reformas do Ensino Superior (Lei $n^{\circ} 5.540 / 68$ ) e do Ensino de $1^{\circ}$ e $2^{\circ}$ graus (Lei n 5.692/71) da década de 1960-1970, momento em que o fenômeno da profissionalização ganha força, ela se constitui a partir de dimensões individuais e sociais, a definição de si mesmos, o reconhecimento pelos outros e a relação com a atividade de ensinar, aspectos que tentam anular as visões do senso comum que tratam a profissão docente como uma semiprofissão, subprofissão, pseudoprofissão, profissão secundária, complementar ou marginal na busca de uma nova identidade, a identidade profissional docente (VALLE, 2002).

Essas construções acerca da profissão do professor enraizadas no imaginário da sociedade contribuem para perpetuar a visão dos docentes, sujeitos que são representados com um perfil de desqualificação pelo seu trabalho, caracterizado como profissão menor, e, portanto, de menor prestígio.

Dessa forma, é preciso levar em consideração os diferentes discursos que são veiculados, referentes ao papel do professor na política de representação dos gestores do Estado no espaço acadêmico; as políticas de verdade da mídia impressa, televisiva e cinematográfica que ajudam a configurar o desprestígio desse profissional e produzem "[...] uma ética e uma determinada relação com eles mesmos, que constituem a experiência que podem ter de si próprios [...]" (GARCIA, 2005, p. 47).

Nesse sentido, as possibilidades de investigação das identidades docentes são múltiplas, dada à imensa variedade das condições de formação e atuação profissional desses sujeitos, a diversidade de artefatos culturais e discursivos envolvidos na produção dessas identidades e a complexidade dos fatores que interagem nos processos de identificação dos docentes com o seu trabalho.

Talvez, um caminho produtivo para a pesquisa não seja investigar a identidade profissional a partir da classe social ou da natureza do processo de trabalho, e sim buscar as diferenças, as descontinuidades, as divisões dessa categoria, privilegiando as narrativas dos professores e das professoras acerca de si mesmos e de seus contextos de trabalho, sendo necessário percebê-los como sujei- 
tos divididos entre aspectos burocráticos, morais, pessoais, profissionais, técnicos, entre outros, e deixar de enquadrar a identidade profissional docente em alguns tipos ideais ou explicá-la a partir de algum elemento fundacional (GARCIA, 2005).

Dessa forma, alguns discursos que são veiculados pelos diversos meios de comunicação referentes ao papel do professor no imaginário da sociedade passam pelas representações que estão em alguns casos cristalizadas quanto à profissionalização à medida que ele se reconhece como participante da prática educativa (GARCIA, 2005).

A partir desses elementos, percebe-se que a identidade profissional docente está ligada ao reconhecimento que o professor tem de si e de seu papel na sociedade, bem como leva em conta a política de representação que instituem os discursos da gestão do Estado e da mídia como divulgadora de "verdades".

\section{CONSIDERACÕ̃ES FINAIS}

Este trabalho possibilitou o entendimento de que o ser professor no universo acadêmico da Instituição pesquisada apresenta-se como um papel complexo, construído socialmente a partir da cultura e revela as amarras dos paradigmas que sustentem as práticas e os discursos obtidos a partir dos depoimentos durante o processo de pesquisa.

Assim, de acordo com a fala dos estudantes entrevistados, pode-se perceber que o ser professor exige uma aceitação de que é um papel inerente ao próprio sujeito que exerce a profissão e não se limita apenas a uma função que se realiza quando se está ministrando aulas. No dizer de Nóvoa (2000, p. 10), “ser professor obriga a opções constantes, que cruzam a nossa maneira de ser com a nossa maneira de ensinar e que desvendam na nossa maneira de ensinar a nossa maneira de ser".
Observou-se, também, que o professor, nos dias atuais, constitui-se num profissional que precisa de uma formação inicial e continuada que possibilitem uma visão que requer uma constante atenção em relação à diversidade de informações as quais chegam a todo o momento através dos diversos meios de comunicação.

Dessa forma, exige-se uma atuação reflexiva e um posicionamento crítico diante da realidade complexa para uma melhor atuação em seu contexto, seja ele qual for.

Além disso, foi possível perceber, junto aos sujeitos da pesquisa, que o fenômeno da identidade profissional docente esteve presente de forma incipiente nos depoimentos.

Esse fato traz indicadores do quanto à profissão do professor necessita ainda de elucidação em relação às suas funções na atualidade, mesmo com todos os avanços teóricos, profissionais, político-econômicos, dentre outros aspectos.

Portanto, a partir das falas dos depoentes temos indícios de que foi possível perceber que a docência ainda é vista na atualidade como profissão menor, uma subprofissão e uma área em que qualquer um que tenha algum tipo de formação, poderá atuar.

\section{REFERÊNCIAS}

BERHENS, Marilda Aparecida. Os paradigmas da ciência: a influência na sociedade e na educação. In: 0 paradigma emergente e a prática pedagógica. 3.ed. Curitiba: Champagnat, 2003.

CASTORINA, José Antonio. 0 debate Piaget-Vygotsky: a busca de um critério para sua avaliação. In: CASTORINA, José Antonio; OLIVEIRA, Marta Kohl de; LERNER, Delia; FERREIRO, Emilia. Piaget-Vygotsky: novas contribuições para o debate. São Paulo- SP: G \& C Associados, 1996. 
DICIONÁRIO DE FILOSOFIA MORAL E POLÍTICA. Instituto de Filosofia da Linguagem. Disponível em: <http://www.google.com.br/\#hl=pt-BR\&biw= 1366\&bih=575\&q=defini $\%$ C 3\%A7\%C3\%A3o+da+ teoria $+\mathrm{cr} \% \mathrm{C} 3 \%$ ADtica $+\& a q=f \& a q i=\varepsilon a q l=\varepsilon o q=\varepsilon f p$ $=8 \mathrm{be} 7758 \mathrm{~d} 8 \mathrm{~d} 6384 \mathrm{a}>$. Acesso em: 20 jan. 2011.

EXPLICATORIUM. Marx Planck. Disponível em: <http://www.explicatorium.com/Max-Planck.Php>. Acesso em: 20 nov. 2009.

GARCIA, Maria Manuela Alves; HYPOLITO, Álvaro Moreira; VIEIRA, Jarbas Santos. As Identidades docentes como fabricação da docência. Educação e Pesquisa, São Paulo, v.31, n.1, jan./abr. 2005, p.45-56.

JODELET, Denise. Representações sociais: um domínio em expansão. In: (org). As representações sociais. Tradução: Lilian Ulup: Rio de Janeiro: UERJ, 2001.

KENSKI, Vani Moreira. Novastecnologias, oredimensionamento do espaço e do tempo e os impactos no trabalho docente. Disponível em: <http://www.serprofessoruniversitario.pro.br/ler.php?modulo=18\&texto=1106. Acesso em: 11 fev. 2011.

MOSCOVICl, Serge. A representação social da psicanálise. Rio de Janeiro: Zahar, 1987.

MINAYO, Maria Cecília de Souza. Introdução à metodologia de pesquisa social. In: $\mathbf{0}$ desafio do conhecimento: pesquisa qualitativa em saúde. São Paulo: Hucitec, 1992, p.19-88.

NÓVOA, António. Universidade e formação docente. Botucatu: Interface. Entrevista, v.4, n.7, 2000. Disponível em: <http://www.scielo.br/pdf/icse/v4n7/13. pdf>. Acesso em: 26 nov. 2009.
O QUE É A ESCOLA DE FRANKFURT. Disponível em: <http://pessoal.portoweb.com.br/jzago/frankfurt. htm>. Acesso em: 20 nov. 2009.

REGO, João. 0 regime autoritário de 1964. Disponível em: <http://www.midiaindependente.org/pt/ red/2004/03/276660.shtml>. Acesso em: 15 nov. 2009.

SUA PESQUISA.COM. Albert Einstein: o pai da Teoria da Relatividade. Disponível em: <http://www.suapesquisa. com/biografias/einstein/>. Acesso em: 20 nov. 2009.

SUA PESQUISA.COM. Charles Darwin: criador do Evolucionismo. Disponível em: <http://www.suapesquisa. com/biografias/darwin.htm>. Acesso em: 20 nov. 2009.

SUA PESQUISA.COM. Friedrich Engels: um dos criadores do Socialismo Científico Disponível em: <http://www.suapesquisa.com/biografias/engels. htm>. Acesso em: 20 nov. 2009.

SUA PESQUISA.COM. Karl Marx: o idealizador do Comunismo. Disponível em: <http://www.suapesquisa. com/biografias/marx/>. Acesso em: 20 nov. 2009.

TODA A BIOLOGIA.COM. Jean-Baptiste Lamarck: teorias importantes para o avanço da Biologia. Disponível em: <http://www.todabiologia.com/pesquisadores/lamarck.htm>. Acesso em: 20 nov. 2009.

VALLE, Ione Ribeiro. Da “identidade vocacional” a "identidade profissional": a constituição de um corpo docente unificado. Perspectiva. Florianópolis, v.20, n. especial, jul/dez, 2002, p.209-230. 
2. Estudante do Curso de Licenciatura em Pedagogia, $7^{\circ}$ semestre, Bolsista de Iniciação Científica (PROBIC) da Universidade Estadual de Feira de Santana (UEFS), vinculado ao Núcleo de Estudos e Pesquisas Aceito em: 8 de Agosto de 2014 